\title{
CAPÍTULO 06: SAÚDE PARA ALÉM DA AUDIÇÃO NO ATENDIMENTO DA CRIANÇA SURDA: CONSTRUÇÃO INTERSUBJETIVA DA CRIANÇA SURDA
}

\author{
CAPÍTULO 06: LA SALUD MÁS ALLÁ DE LA AUDICIÓN AL SERVICIO DEL \\ NIÑO SORDO: CONSTRUCCIÓN INTERSUBJETIVA DEL NIÑO SORDO
}

\section{CHAPTER 06: HEALTH BEYOND HEARING IN THE SERVICE OF THE DEAF CHILD: INTERSUBJECTIVE CONSTRUCTION OF THE DEAF CHILD}

\begin{abstract}
Pablo Vinicius do Nascimento Pinto하 Flávio Arthur Morais Cabral ${ }^{2}$; Silvano Martins da Silva Filho ${ }^{3}$; Samuel
\end{abstract} Nascimento Neto ${ }^{4}$; Cristiane Raquel Souto Zilbermintz ${ }^{5}$

DOI: $\underline{\text { https://doi.org/10.31692/978-65-88970-04-1.65-70 }}$

\section{INTRODUÇÃO}

Considerando que o ser humano se constitui a partir de suas construções no mundo, podemos questionar de que forma o faz e como o faz. Em nossas vivências, clínica e acadêmica, vemos um olhar patologizante sobre o sujeito, que em dadas vezes separa o indivíduo de sua subjetividade e o observa apenas como um órgão lesado. Helena Blavatsky, uma das marcantes fundadoras da Filosofia Teosófica, apreende um conceito do qual podemos usufruir: Para alcançar a plenitude, é necessário abandonar o que a pensadora chama de "heresia da separatividade". Colocando a fragmentação como um ato que afasta quem o faz, da plenitude. Contudo, há campos de força que exercem poder sobre o fazer dos profissionais da saúde, envoltos em um tradicionalismo organicista e fragmentalizador, que em si mesmo, tende a direcionar as práticas para a patologia de maneira isolada. Este padrão em nossa visão tende a se repetir nas ideologias do fazer clínico. Segundo Barbosa (2011), não podemos enxergar um sintoma de forma isolada, já que ele é uma parte da criança, que faz parte da sua totalidade.

Tendo em vista a compreensão do sujeito nessa perspectiva, queremos elucidar para, além disso, evidenciando esse olhar holístico; várias visões da constituição do sujeito (aqui posto, sujeito surdo), de sua subjetividade, história de vida, de como se enxerga e como compreende, tudo isso constitui o sujeito. Endossamos aqui a importância da apreensão de perspectivas que abordam vários modos de ser, várias facetas do ser humano. Dessa objetivamos levar aos atuantes interventores na surdez, como: profissionais estudantes, profissionais da educação, assistentes sociais, pais e familiares, surdos, tradutor-

\footnotetext{
${ }^{1}$ Fonoaudiologia, Universidade Católica de Pernambuco, pabloviniciusdonp@ gmail.com

2 Psicologia, Universidade Católica de Pernambuco, flavioarthurmorais@ gmail.com

${ }^{3}$ Psicologia, Centro Universitário Maurício de Nassau, silvanomartins614@ gmail.ce

${ }^{4}$ Fonoaudiologia, Universidade Católica de Pernambuco, samuelnasneto@ gmail.com

${ }^{5}$ Mestra, Universidade Católica de Pernambuco, cristiane.zilbermintz@unicap.br
} 
intérprete de língua de sinais e todos aqueles que se interessarem por essa temática, a lidarem com seu fazer de forma integrada, vendo o sujeito como mais que o todo e não apenas como a soma das partes; dotado de todos os atributos constituintes de sua identidade e linguagem.

\section{FUNDAMENTAÇÃO TEÓRICA}

O sujeito se constitui a partir da linguagem através das relações que o envolvem. Linguagem esta, que se manifesta de maneira multimodal para então culminar na fala propriamente dita (Ribeiro et alt, 2018). Desde o ventre materno o bebê vai sendo constituído simbolicamente e fisicamente.

Ao nascer, estabelece uma relação simbiótica com a pessoa que exerce maternagem. Levando em consideração o olhar da Gestalt em relação à constituição da criança compreende-se através da relação. Uma pessoa existe quando seu self é diferenciado do outro, e quando ele conecta o self e o outro (YONTEF, 1998). Na psicanálise ao nascer o bebê se entende como uma extensão do corpo da mãe, em seu desenvolvimento, passa a se perceber como indivíduo separado e, estabelece relação, fazendo iniciativas comunicacionais ao se colocar em um lugar de satisfação do outro (O que Lacan chama de "objeto de gozo"). O bebê o faz através da linguagem, desenvolvendo o que Freud (1905) chama de circuito pulsional.

Autores que direcionam seu olhar para o desenvolvimento da linguagem da criança surda como Quadros (2008), discorrem sobre o processo de aquisição da linguagem da criança. Considerando o desenvolver da aquisição da língua, se dando de forma equivalente nas modalidades de línguas de sinais ou falada, perpassam por locais do desenvolvimento, o que Quadros chama de estágios de aquisição de linguagem. Que, pautada nas questões maturacionais e de cognição, se manifesta de maneira paralela para ambos os sujeitos (surdos e ouvintes) haja vista que, em sua organogênese, a surdez de ordem primária não repercute nas questões referentes ao desenvolvimento maturacional, neurológico e cognitivo. A autora, 2008, conceitua os estágios de desenvolvimento da língua como: Pré-linguístico, no qual se manifestam o balbucio manual e vocal, sendo este comum para ambos; o estágio de um sinal, para a criança surda e de uma palavra para a criança ouvinte (aqui referida como vocalização).

Em seguida aparecem as primeiras combinações de palavras e sinais e o refinamento na língua vai se expandindo para múltiplas combinações. Assim sendo, a criança surda tem suas manifestações linguísticas análogas ao da criança ouvinte. Em se tratando de comunicação oral esse processo se diferencia a partir da vocalização, como afirma Quadros (2008). 
Para tanto, a criança surda (não implantada) manifesta a construção de sua intersubjetividade utilizando os recursos visuais majoritariamente. Com a instalação do implante coclear a construção dessa linguagem advém de novos sentidos. O implante coclear (IC) se caracteriza por ser uma prótese computadorizada que é inserida cirurgicamente na cóclea, com o objetivo de substituir parcialmente as funções do órgão espiral (a cóclea), fornecendo impulsos elétricos para a estimulação direta das fibras neurais. (Bevilacqua, 2004).

Com o uso da tecnologia, a criança surda, seria direcionada, desde o início de sua construção subjetiva para vivências associadas a o ouvir. O que parece ser um alavancar fantástico de considerar essa possibilidade para o sujeito surdo, guiar o pensamento de que este surdo irá ouvir, e que com isso deixará de ser surdo. Entretanto, a capacidade de ouvir o faz integrado à comunidade ouvinte? Ou considera-se esse sujeito surdo-ouvinte? Hajam vistas as questões que permeiam sobre a identidade surda ou a identidade ouvinte.

Ainda neste contexto, um questionamento que se projeta é: um sujeito astigmata que usa óculos para correção de sua visão, o faz não-astigmata? Ainda uma pessoa deficiente física, que usa próteses em seus pés, por exemplo, sem as quais não andaria, deixa de ser deficiente físico? Para tanto, questionamos aqui, não-surdez produzida à partir da instalação tecnológica, ou a surdez ouvinte?

Apoiados em Perls (1988), que afirma, cada um é o que é, com suas características individuais, devido a seu relacionamento com o outro e o todo. Podemos então inferir que apesar de ser a mesma patologia, o experienciar é único para cada indivíduo, e as implicações serão singulares. É importante que esse olhar seja para além disso pois ao tentar enquadrar tudo em um mesmo conjunto, as peculiaridades não estarão sendo compreendidas.

Considerando as experiências de ser surdo (não implantado), a comunidade surda busca resistir ao imperativo da língua oral como uma primeira língua e à desvalorização das línguas de sinais. Participar da comunidade surda para muitos destes significa iniciar-se em uma linguagem, possibilitando não somente a comunicação, mas também o conhecimento de mundo e o desenvolvimento do pensamento individual, o que Vygotsky (1989) chama de “discurso egocêntrico". Para além dos aspectos linguísticos, essa comunidade empodera e defende o sujeito diante de um contexto de isolamento social. A troca entre surdos e surdos proporciona-os a solução de problemas do dia-dia, o posicionamento político diante dos seus direitos, a valorização e potencialidade das singularidades Dirksen, Bauman e Murray (2014) contrapõem à deficiência chamando de "deaf-gains", ou ganhos surdos. 
Contudo, para vertentes da psicologia como a Gestalt que faz parte das abordagens da Psicologia, O ser humano nesta abordagem é um constante vir a ser, é contínuo, sendo assim, não se reduz a uma categoria. Como encaixá-lo em uma categoria fixa, que afirma que ele é isso ou é aquilo? AGUIAR, (2014). Para a Gestalt o diagnóstico apresenta-se apenas como um modo de ser. Vale voltar-se a importância da singularidade individual de cada pessoa apesar dos achados orgânicos. Em termos diagnósticos essa singularidade aponta para o fato de que sintomas semelhantes apresentam-se em crianças diferentes, com histórias diferentes, mergulhadas em campos diferentes e, portanto, com significados diferentes (AGUIAR, 2014).

Ademais em se tratando da língua propriamente dita (como a língua portuguesa, por exemplo), já manifesta como sendo a direcionante para fatores culturais, sociais e, portanto identitários podemos experienciar sua arbitrariedade. O signo linguístico, como sendo átomo da linguagem, como afirma Saussure, apontando que a estrutura do signo linguístico é por si mesma arbitrário, a exemplo da palavra "bola" enquanto forma, do ponto de vista morfossintático, em nada referencia o objeto esférico e cheio de ar que conhecemos. Para, além disso, o som da palavra "bola" também não referencia o objeto. O sujeito agora recémimplantado precisa ressignificar as estratégias de interpretação do mundo e identidade a partir das novas percepções. É nesta nova cadeia de significantes que a constituição subjetiva do sujeito sofre modificações; a forma de percepção do mundo, de si e do outro ganham novas perspectivas. Bem como os sistemas de relações que são estabelecidos. A linguagem do sujeito surdo e, portanto sua identidade é direcionada à de um sujeito que ouve (E que continua surdo?).

Diante do dito acima, fica claro que o modelo de cuidado que temos é por vezes limitado e tolhe as subjetividades de pessoas surdas. Compreender o ser humano como biopsicossocial é compreender também o impacto que a dimensão psíquica e a social têm em sua saúde. Entender sobre a importância da possibilidade de acesso a língua, a comunidade surda, o capacitismo, a diagnose integrada, o processo constitutivo dessas pessoas é pensar er uma saúde integrada que respeita o lugar dos surdos no mundo e não reproduz violências médicas.

\section{METODOLOGIA}

A metodologia tem caráter qualitativa bibliográfica, extraindo os re bases de dados secundários. A pesquisa qualitativa, segundo Deslandes (2004), não se baseia no critério numérico para poder garantir sua representatividade. 
A seleção inicial se deu com base na leitura dos títulos, a fim de observar a adequação das temáticas com a metodologia do estudo. Observando a relação com a pergunta de pesquisa foi feita a leitura dos resumos, livros e os artigos selecionados para serem lidos na íntegra, a seleção dos dados foi inspirada a partir das três fases fundamentais para a análise do conteúdo instituídas por Bardin (2011): Pré-análise, exploração do material, tratamento dos resultados (interferência e interpretação).

\section{RESULTADOS E DISCUSSÃO}

A compreensão dos processos intersubjetivos ligados à constituição do sujeito e o impacto da construção da identidade surda, levando também em consideração o uso de tecnologias de promoção auditiva, são fundamentais para o desenrolar dos processos realizados para o desenvolvimento da linguagem e interpretação do mundo. Cabe aos profissionais e pesquisadores da saúde tomarem conhecimento sobre esses fatores tão determinantes para o alavancar do processo terapêutico de seus pacientes na atuação clínica.

\section{CONCLUSÕES}

Respeitar e compreender a individualidade da criança surda é fundamental para que haja progresso e desenvolvimento desse sujeito tanto do ponto de vista clínico-individual quanto sociocultural.

\section{REFERÊNCIAS}

AGUIAR, Luciana. Gestalt-terapia Com Crianças: teoria e prática. São Paulo: Summus. 2014.

BARBOSA, P. A criança sob o olhar da Gestalt-terapia. Rio de Janeiro: IGT na Rede 2011.

BARDIN,L. Análise de conteúdo. São Paulo:Edições 70, 2011.

DESLANDES, S.F. A construção do projeto de pesquisa. In: MINAYO, M.C.S. Pesquisa social: teoria, método e criatividade. Rio de Janeiro: Vozes, 2004.

RIBEIRO, M. C. M. A; AZEVEDO, A. P. M. B. Por uma introdução teoria da multimodalidade: uma abordagem panorâmica para professores de língua(gem). Brasília: Revista Horizontes De Linguística Aplicada, 2018.

FREUD, S. (1905) Três ensaios sobre a teoria da sexualidade. Edição Standard Brasileira 
das obras completas, vol. VII. Rio de Janeiro: Imago, 1976.

QUADROS, R.M. Aquisição da Linguagem. In: QUADROS, R.M. Educação de surdos: a aquisição da Linguagem. São Paulo: Artmed Editora, 2008.

H-Dirksen, L; BAUMAN, Z; MURRAY, J,J.Estudos surdos no século 21: "Deaf-gain" e o futuro da diversidade humana. In: ANDREIS-WITKOSKI, S; FILIETAZ, M.R.P. (Orgs). Educação de surdos em debate. Paraná: Ed. UTFPR, 2014.

VYGOTSKY, L.S. Concrete human psychology. Rússia: Journal of Russian \& East European Psychology, 1989.

PERLS, F. A abordagem gestáltica e a testemunha ocular da terapia. Rio de Janeiro: LTC, 1988.

YONTEF, G.M. Processo, Dialógico e Awareness. São Paulo: Editora Summus, 1998. 